\title{
Conceptualizing a Theoretical Model for School-Centered Adolescent Physical Activity Intervention Research
}

\author{
Ang Chen and Gregory R. Hancock
}

\begin{abstract}
Adolescent physical inactivity has risen to an alarming rate. Several theoretical frameworks (models) have been proposed and tested in school-based interventions. The results are mixed, indicating a similar weakness as that observed in community-based physical activity interventions (Baranowski, Lin, Wetter, Resnicow, \& Hearn, 1997). The theoretical models were decontextualized, thus are unable to address issues central to adolescents' physical activity behavior. In this article, we propose using a theoretical model derived from school-based research on learning behavior change. We review related research on adolescents' physical activity to demonstrate the relevance of using the model to study the dynamic impact of personal, school curriculum, and community variables on adolescent physical activity. We also translate the conceptual model into empirically testable cross-sectional and longitudinal latent growth models and propose concrete steps researchers can take to design empirical studies to examine them. We believe that research studies guided by the proposed conceptual and empirical models will provide useful data for us to better understand the mechanisms of adolescent physical activity motivation and behavior change.
\end{abstract}

Physical inactivity in adolescents has risen to an alarming rate. It is a consensus that the school-centered, especially physical education-based, interventions are the most appropriate avenue for all school-age children (Corbin, 2002). Several theoretical frameworks (models) have been proposed and clinically tested for effectiveness in schools. Results are quite mixed in terms of their actual effects on changing children's long-term physical activity behavior (Stone, McKenzie, Welk, \& Booth, 1998). The mixed results may indicate a similar weakness as that observed in community-based physical activity interventions (Baranowski et al., 1997), that the theoretical models were decontextualized and were unable to address issues central to adolescents' physical activity behavior. Most theoretical models derived from outside school physical education and were designed for treating adult obesity or physical inactivity (Chambliss, 2004), rather than nurturing and sustaining the desired behavior of physically active living. In addition, the application of the

Ang Chen is with the Dept of Kinesiology, University of Maryland, College Park, MD 20742. E-mail: angchen@umd.edu. Gregory R. Hancock is with the Dept of Measurement, Statistics, and Evaluation, University of Maryland, College Park, MD 20742.. 
models is tailored mostly for adult populations with high risk, rather than seemingly ordinary but risk-behavior-prone children and adolescent population. The usefulness of the models for school-age children and adolescents can be limited (see Chambliss 2004 for a description of some models).

Studies on the models seldom measure school curricular and instructional variables. Thus, it is difficult to apply them directly in designing effective physical education intervention programs without drastic modification. For example, the transtheoretical model was developed for adults to control smoking (Prochaska \& DiClemente, 1983). Applying the model for changing other behaviors has been challenged (Bandura, 1997) and its effects in a school-centered, especially physical education intervention program may be questionable in terms of context, population, and the target behavior itself. When a model is modified with drastic change in its components or the relationships among them, the model's relevance could be affected. Another model often used is based on self-efficacy theory. The theory has been effective in predicting adolescent's motivation in sports settings (Moritz, Feltz, Fahrbach, \& Mack, 2000); its effectiveness in changing their daily physical activity motivation and behavior has yet to be observed empirically.

Epistemologically, these models are centered on psychological constructs that are for the understanding of individual differences. Rather, changing of behavior is a holistic process that is influenced by the environment that usually consists of important variables external to the individual. In the case of school-centered physical activity intervention, it is the physical education curriculum that has tremendous influence on children's in-class physical activity behavior change (McKenzie, 2001; Stone et al., 1998). Presumably, a theoretical model derived from schoolbased research that successfully addresses adolescents' motivation and behavior in school learning may stand a greater chance to be successful in addressing their physical activity motivation and behavior change.

In this article, we will describe and elaborate such a theoretical model. We will review related research on adolescents' physical activity motivation and behavior change to demonstrate and discuss the relevance of using the model to study the dynamic impact of personal, school curriculum, and community variables on adolescent physical activity behavior. We will also translate the conceptual model into empirical models to demonstrate specific empirically testable relationships among the variables and propose steps researchers can take to design empirical studies to examine the model.

\section{A Model for Physical Activity Motivation and Behavior Change}

One reason for the decrease of physical activity in adolescents is a significant decline of their interest in and motivation for physical activity. Motivation, as a psychological construct, is defined as the mental process that initiates and sustains goal-directed activities (Pintrich \& Shunk, 2002). It consists of energy needed to put forth effort and direction or goals to pursue. Adolescents usually are full of energy but lack direction, and may invest energy for irrelevant goals (Schneider \& Stevenson, 1999). Robinson (1999) reported, for example, that children were able to reduce their TV time after a TV time reduction intervention, but their physical 
activity remained unchanged. The finding suggests that children may need assistance to direct their energy to relevant activities, such as physical activity.

Different from that of adults, adolescent motivation is highly situational, characterized by spontaneity derived from the interaction between an individual and a specific situation. Adolescents, for example, can be easily motivated by situational interest defined as the appealing effect of an activity on individuals (Hidi \& Anderson, 1992; Mitchell, 1993). Physical activities with high situational interest (e.g., fun games, being with friends, and excitement of competition) can be offered to adolescents in various settings including physical education classes to change their short-term behaviors. Conversely, a sustained behavior relies on self-initiated motivation, which refers to the drive to engage in an activity based on a person's self-concept system consisting of his/her perceived competence, self-efficacy, and expectancy beliefs and values in the activity (Wigfield \& Eccles, 1992).

Self-initiated motivation is independent from the immediate environment. Adolescents who demonstrate high self-initiated motivation are able to determine their goals, actively seek opportunities, and regulate their behaviors for achieving the goals. However, there is often a gap between situational motivation and self-initiated motivation in adolescents. Goodlad (1984), for example, found in a national sample of K-12 students that physical education was the most liked content among all subjects offered in school because it was fun (situationally motivating). Yet, the students considered it of the lowest value. They can be motivated to actively participate in physical education classes, but may not adopt a physically active lifestyle. It is apparent that understanding how children transform situational motivation to self-initiated motivation is the key to helping adolescents develop and sustain physical activity motivation and behavior.

\section{A Conceptual Model}

As we reasoned above, it is relevant to situate the issue of adolescent physical activity motivation and behavior change within a theoretical framework that is derived from school-based research and theories. During a triangulation of research findings from physical activity intervention and education, we adopted a conceptual model to help understand the issue of adolescent motivation and behavior change from a holistic perspective. As can be seen in Figure 1, a central emphasis of the model lies in helping adolescents internalize situational motivation into self-initiated motivation. The model is originated from educational psychology research to describe learning behavior change and to assist the learner in adopting effective learning behavior (Alexander, Jetton, \& Kulikowich, 1995). It is important to notice that, from an integration perspective, the model asserts that learning behavior change depends on the collective impact of changes in knowledge, self conception, and the sources of motivation. At various developmental stages, the outcome behavior changes as a result of the changes that are occurring in these variables. By adopting this model, we accept an important assumption that physical activity behavior change shares the characteristics of learning behavior change with three milestone stages: acclimation, competence, and proficiency.

At the Acclimation Stage, adolescents have little knowledge and skills needed for pursuing an expected behavior. Their self-concept systems are characterized by inaccurate perceptions of competence, self-efficacy, and self body image. At this 


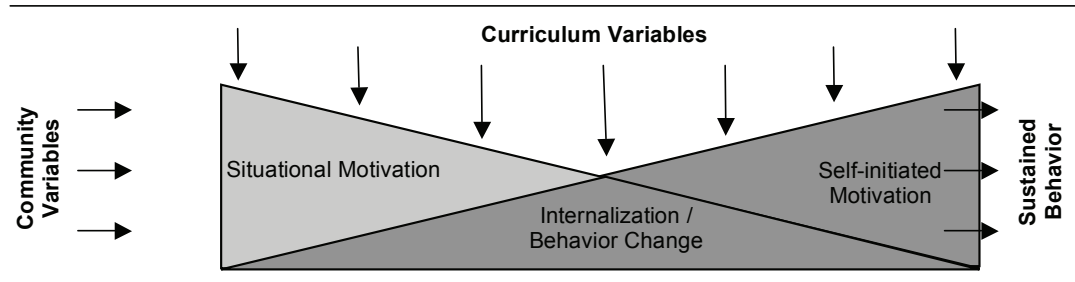

Hypothesized Behavior Change Stages

$\begin{array}{llll}\text { Personal Variables } & \text { Acclimation } & \rightarrow \text { Competence } \rightarrow & \text { Proficiency } \rightarrow \\ \underline{\text { Knowledge \& skill }} & \text { Little } & \text { Developing } & \text { Sufficient } \\ \underline{\text { Self-concept system }} & \text { Inaccurate } & \text { Accurate } & \text { Very accurate } \\ \underline{\text { Motivation source }} & \text { Situational } & \text { Situational \& Personal } & \text { Person - initiated } \\ \text { Expected behavior } & \text { None } & \text { Appearing } & \text { Stabilizing }\end{array}$

Figure 1 -The theoretical model for physical activity motivation and behavior change

stage, adolescents are motivated by situational motivators (e.g., fun in activities, game partners), not self-initiated motivators. Consequently the expected behavior is situation-induced, not self initiated or sustained. It is not difficult to understand that most interventions are designed for children at this stage. They rely on situation-based motivators to enhance knowledge about and competence for physical activity.

At the Competence Stage, adolescents begin to develop knowledge and skills needed for the development of expected behavior. In physical activity intervention, the knowledge about health benefits of physical activity and skills needed to follow scientifically sound exercise regimens in various physical activity forms are especially helpful. The knowledge and skills form a foundation for adolescents to assess competence accurately and to develop accurate self-efficacy beliefs. At this stage, adolescents are beginning to rely on self-initiated motivation derived from internalizing situational motivation. For example, they may begin to realize that physical activity is not only fun (situational motivation), but also beneficial to health (value-based self-initiated motivation). As a result, the expected behavior begins to emerge. Appropriate interventions are critical for adolescents at this stage. Their behavior can further develop or diminish, depending on how effectively situationinduced motivation can be internalized into self-initiated motivation. Adolescents need to become self assured that the knowledge and skills they learn can indeed help them in their lives. In education, Jacobs, Lanza, Osgood, Eccles, and Wigfield (2002) have demonstrated the long-term positive effect on learning motivation and behavior change through enhanced expectancy for success and task values.

At the Proficiency Stage, adolescents have acquired sufficient knowledge and skills for a deep understanding of the values in the expected behavior. They can assess their competence accurately and have developed appropriate self-efficacy 
beliefs. Further, the accurate self-concept system will allow them to develop appropriate strategies to overcome barriers encountered in pursuing the expected behavior. The adolescents become self motivated, instead of relying on situational motivators. The expected behavior becomes stabilized and eventually sustained. It is logical to reason that interventions are not necessary for the adolescents in this stage. They are self motivated, will continue physical activity, and will be able to modify their behavior through gaining new knowledge and skills.

In addition, the model acknowledges the function of certain community presage variables that set a prior stage for adolescents before they enter into the motivation and behavior change process. Several variables, for example, community resources for physical activity and safety (Voorhees, Clifton, Whitt, \& Young, 2004), may be more conducive to a physically active lifestyle for adolescents than for others. The model also suggests that an effective physical education curriculum is central to behavior change. School culture and environment are based on a curriculum (Goodlad, 1984). The physical education curriculum should be able to reinforce positive effects of the community variables that motivate and help adolescents to overcome negative effects of those variables that may constrain their motivation. Educated in an effective physical education curriculum, an adolescent can be expected to become able to internalize situational motivation into self-initiated motivation and to develop and sustain physically active living. For example, an adolescent can only be motivated to exercise together with peers (situational motivation). An effective physical education curriculum should be able to help the adolescent develop strategies to become motivated to exercise on his/her own when his/her peer group cannot exercise together (self-initiated motivation).

The model also suggests that adolescent physical activity motivation and behavior change follows a progression from the acclimation stage to the competence stage and to the proficiency stage. In this process, motivation and behavior changes are a function of dynamic interactions of knowledge and skill acquisition, self-concept development, motivation sources, and behavior expectations. At each stage, the interactions are influenced by community variables and the curriculum. Certain changes in community and curriculum variables may bring about changes in motivation and behavior at a particular stage but may not be effective for those at other stages. For example, situational motivators (e.g., fun, exercising with peers) will attract adolescents at the acclimation stage to various physical activities (Chen \& Darst, 2001), while emphasizing physical activity values will motivate those at the competence stage to adopt various strategies to defy the challenges from inside and outside self (Wigfield, 1994).

\section{Operationalization of the Conceptual Model for Research}

We operationalize the conceptual model into two families of empirical models that physical education researchers are able to test with meaningful manipulation of curriculum conditions. Based on findings from classroom-based research (Alexander, 2006), an a priori model can be established such as that described in Figure 2. The model describes causal pathways that illustrate cross-sectional relationships between adolescent physical activity motivation and behavior change (the dependent variables) and blocks of influential personal, curriculum, and 


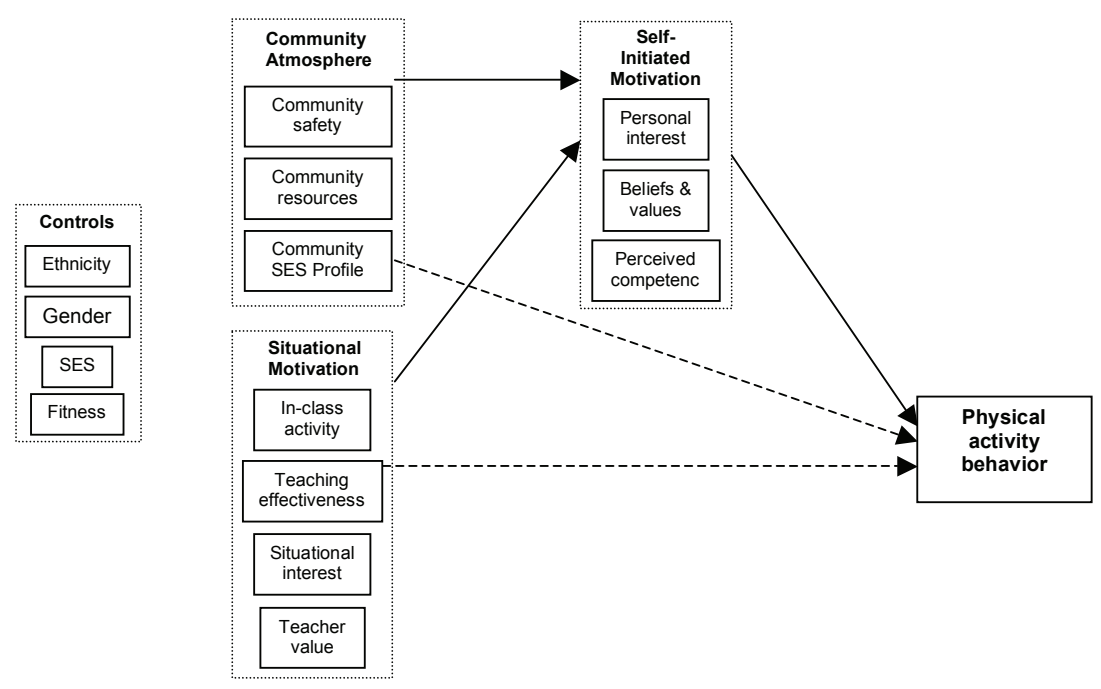

Figure 2-A path model for adolescents' physical activity motivation and behavior change

community variables. This model suggests that sustained physical activity behavior is directly dependent on the block of self-initiated motivation sources, which is itself dependent on community variables and situational motivators.

Physical activity motivation and behavior change is a long process. Figure 3 presents a family of longitudinal, multi-domain latent growth models that researchers can employ to examine long-term motivation and behavior change resulting from the changes in the curriculum and community variables over time. The family of multi-domain linear growth models describes changes that occur over time in each influential variable block and their impact on physical activity motivation and behavior (top part of Figure 3). Longitudinal impact of the dynamic interaction among the influential variables on physical activity motivation and behavior change can be determined in a combined model with each initial change (initial slope) in each influential variable block taken into account, with controlling the effects of the control variables (bottom part of Figure 3). The application of the empirical models in research will be discussed in depth in the Possible Research Strategies section later in this article.

\section{Evidence and Rationale for Selecting Influential Variables}

It is in schools and homes that adolescents construct their physical activity behavior (Kahn et al., 2002). Sallis, Prochaska, and Taylor (2000) summarized that 


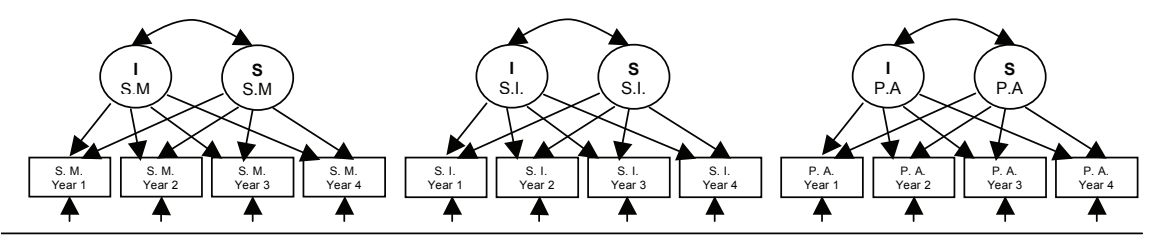

Note

S.M. $=$ Situational Motivation S.I.=Self-Initiated Motivation C.A. $=$ Community Atmosphere P.A.=Physical Activity Behavior I=Intercept $\mathrm{S}=$ Slope

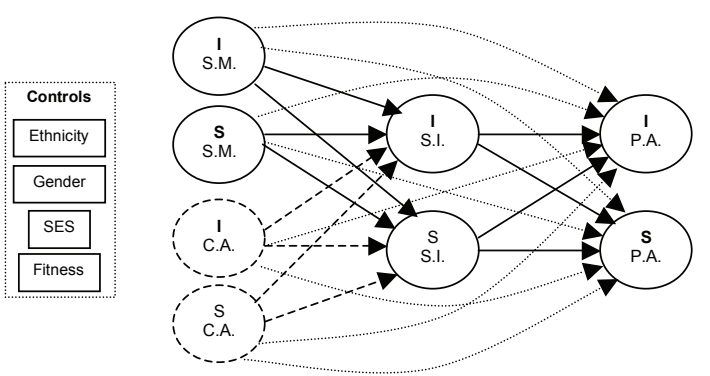

Figure 3-Multi-domain latent growth model describing causal relationship change over time

adolescent physical activity behavior is associated with 9 demographic variables, 35 psychological variables, 30 behavioral variables, 23 social variables, and 7 physical environmental variables. Although a few variables have been found consistently associated with adolescent physical activity, findings about influences from these variables have been inconclusive. Based on a review of the literature, we postulate that key explanatory variables should be understood at the personal, curricular, and community levels and studied in an integrated manner.

\section{Personal Level Variables}

At the personal level, it is important to determine the variables that directly contribute to physical activity behavior and its longitudinal variation. Ethnicity, gender, age, physical characteristics, personal fitness level, and home socioeconomic status have been repeatedly found to be associated with physical activity behavior (Sallis et al., 2000). But they may have little intervention value because they are difficult to manipulate both in research and in life (Kahn et al., 2002). They should be considered as control variables in intervention studies. Physical ability related perceptions, expectancy values in physical activity, and personal interest in physical activities are considered direct causal variables (Kohl \& Hobbs, 1998). Collectively, they compose a block of variables that influence self-initiated motivation.

Both causal and control variables have been considered to be either positive or negative correlates of physical activity for adolescents. Some have been determined to be indeterminates because of inconclusive findings. But all are recommended to be focused on in future research (Sallis et al., 2000). There are, however, findings from educational research suggesting that a focused intervention should target a few important causal variables that contribute to significant behavior change in 
adolescents. We believe adolescents' perceived values and personal interests in physical activity are important sources of motivation for their self-initiated motivation and behavior.

Perceived Values. Motivated behavior is characterized by voluntary choices, persistent effort, and measurable performance improvement/achievement. These indicators of motivation are found to be directly associated with adolescents' expectancy for success and perceived task values in specific activities (Wigfield \& Eccles, 1992). Expectancy for success is defined as individuals' beliefs about how well they will do in upcoming activities. According to Wigfield and Eccles (1992), perceived values include attainment value, intrinsic value, utility value, and cost in the activities. Attainment value refers to personal importance of success in an activity. Intrinsic value is the enjoyment the individual gains from the activity. Utility value is the perception of the worth of the activity in relation to current and future goals in life. Cost, a critical component, refers to the negative aspects of engaging in the activity, such as fear of failure, lost opportunities from choosing one activity over the other (Wigfield, 1994). Research on adolescent expectancy and task values have demonstrated that expectancy beliefs predict actual performance, whereas perceived task values predict motivation for future pursuit of the activity (Wigfield \& Eccles, 1992).

A decade-long longitudinal study that assessed changes of expectancy and task values of children and the impact of the changes on motivation in learning and sports revealed that children are able to develop a self-concept system with many beliefs about self and the activities they engage in (Jacobs et al., 2002). With physiological and psychological development, these beliefs eventually are integrated in a stable self-concept system to inform an activity-specific expectancy for success in a specific domain (e.g., in physical activity). A value system is also developed simultaneously by children and adolescents attaching the values (attainment, intrinsic, utility, and cost) to the activity they are expected to engage in. The value system eventually forms the basis of motivation that motivates (or demotivates) them to take part in the activity and determines the level of effort of engagement.

Expectancy and task values are domain specific. In different activity domains such as mathematics and sports, children and adolescents can demonstrate drastically different expectancy for success and appreciation of task values (Eccles \& Wigfield, 1995). The10-year longitudinal data on children-adolescents motivation for different school subjects (Jacobs et al., 2002) revealed that children's perceived competence and task values decline steadily from elementary to high school. The decline of perceived physical competence and values for sports is characterized by a curvilinear pattern with acceleration occurring during the same years (grades 6-9, Jacobs et al., 2002) when the sharpest decline of physical activity occurs for both boys and girls (Caspersen, Pereira, \& Curran, 2000).

The decline may be explained with the findings from a classic study along this line. According to Eccles and Wigfield (1995), children's expectancy beliefs and task values work hand-in-hand to enable them to distinguish and evaluate personal competencies and activity values. Once children become able to distinguish what they are good at and what they value, they are more likely to use value information in making their motivation decisions. Although the expectancy beliefs play a critical role in motivating children and adolescents to engage in an 
activity at hand, perceived task values may have a stronger and longer influence on children's motivation to continue an activity or to become committed to a new activity in the future.

Adolescent expectancy beliefs and task values, developed through their previous experiences with physical activity (especially sports), play a significant role in motivation and behavior change. The brief summary of research findings indicate the importance of teaching task values in physical activities to children during their adolescent years when the sharpest decline of their expectancy for success, task values, and physical activity is occurring simultaneously (Caspersen et al., 2000; Jacobs et al., 2002). In addition, the findings confirm that interest (intrinsic value) and meaningfulness (utility value) in specific tasks or activities are potential motivational sources important to physical activity behavior change.

Personal Interest. It has been long assumed that interest motivates children in school work and in life (Dewey, 1913). Interest, often yielding pleasant emotions, is often considered to be associated with non-competence purposes in the learning process (Sansone \& Smith, 2000). Development in educational research, however, has helped researchers change this view and re-conceptualize interest as a dichotomous framework that consists of personal interest and situational interest. Personal interest refers to a person's psychological disposition in preference of an activity or an action. Situational interest is defined as the appealing effect of characteristics of an activity on individuals (Krapp, Hidi, \& Renninger, 1992). Both interests have been described as a person-environment (e.g., activity, events, ideas, objects) interactive construct (Hidi \& Harackiewicz, 2000). Both are content-specific and have both cognitive and affective components. In addition, it has been argued that interests are key to student motivation in all learning stages (Alexander et al., 1995).

In physical activity research, personal interest is often measured as a person's liking of particular physical activities. For example, Lumpkin and Avery (1986) surveyed university students to determine whether they were interested in specific activity course offerings. They found that college students were predominantly interested in taking courses of individual sport more than taking those of team sports. It has been reported also that due to social influences males and females can develop differentiated personal interest in physical activities (Clifton \& Gill, 1994). At an early age, boys begin to show preferences for team sports, while girls begin to favor rhythmic activities (Lee, Fredenburg, Belcher, \& Cleveland, 1999).

High personal interest is associated with motivated behavior. Based on a comprehensive meta-analysis, Schiefele, Krapp, and Winteler (1992) have reported that personal interest has a significant average correlation of above 0.30 with achievement across all major content areas. Educational researchers (Hidi, 1990; Schiefele et al., 1992; Hidi \& Anderson, 1992) concluded that becoming personally interested leads students to a behavior of high-level engagement required for high-level achievement. Csikszentmihalyi (1990) has identified personal interest as a "flow" state in which a person is completely motivated by his/her personal interest and becomes inseparable from the activity. This personal interest driven motivation and behavior can be seen when a scientist is engaged in an experiment, a dancer or an athlete in a peak performance, and a student engaged in a meaningful assignment. 
Personal interest is considered as evolving along with a person's knowledge repertoire and value system (Krapp et. al., 1992). It is rooted in personal beliefs determined by knowledge and values about an activity. Thus, it is very stable and difficult to change within a person. Yet, because individuals vary in their knowledge and values, there are tremendous individual differences in personal interests. It is difficult to decide how much effort one should invest in using adolescents' personal interests to facilitate physical activity behavior change. To a certain extent, making such a decision itself is impossible (Hidi \& Anderson, 1992).

The development of values and personal interest is assumed hand-in-hand. For adolescents to become self motivated for physical activity, they should have become personally interested in the activities and understood the values of physical activity. Based on the model (Figure 1), this will occur when adolescents are at the stage of proficiency where they have developed knowledge and values of physical activity and accurate assessment about their competence. Until then, they will rely on situational motivators that may be internalized into their personal self-concept system (Harter, 1988). Thus, it is important for intervention program designers to realize the limitation of the motivation strategies based solely on enhancing personal interest for adolescents who are at the acclimation and competence stages.

\section{Curriculum Variables}

The physical education curriculum has a significant impact on children's physical activity motivation and behavior in school (Stone et al., 1998). In research, motivation and curriculum have rarely been studied together, although each has been within theoretical frameworks central to itself. In physical education, motivation issues are conceptualized mainly as students' psychological disposition of achievement goals, interest, and perceived adaptation to learning tasks, teaching methods, and rewarding systems. This conceptualization tends to overlook the role that the curriculum plays in motivation (Burke, 1995).

Physical education curriculum is a field of study in itself. Research on curriculum has provided a large body of knowledge suggesting that the curriculum is the cornerstone of the school culture (Beyer \& Apple, 1998) and situational motivation (Schneider \& Stevenson, 1999). In the United States, curricular decisions are made at the local school district level and are often based on educational values of the curriculum designers (Jewett, Bain, \& Ennis, 1995). These values create and enforce a particular academic culture and have ultimate impact on the outcomes of students' behavior change.

Teacher Value Orientations. Curricular decisions are based on curricular developers' educational values. These values are often reflected in specific content selected to teach to the students (Ennis, 1992). In a number of studies, it was found that physical education teachers' educational values play a decisive role in their willingness to teach a curriculum (Ennis, 1994; Ennis \& Chen, 1993, 1995; Ennis, Chen, \& Ross, 1992; Ennis, Cothran, \& Loftus, 1997; Ennis, Ross, \& Chen, 1992; Ennis \& Zhu, 1991). Using the Ennis Value Orientation Inventory (Ennis \& Chen, 1993; Ennis \& Zhu, 1991), Ennis identified five basic value orientations. The disciplinary mastery orientation directs teachers to focus on student mastery of factual knowledge and fundamental skills of movement, exercise, and sport. 
The learning process orientation emphasizes teaching students how to learn. The self actualization orientation places a high priority on developing students' selfesteem and self confidence by helping them recognize their needs and interests in exercise. The ecological integration orientation takes a holistic approach to physical education to balance mastery of knowledge and skill with students' personal needs and interests. The social responsibility orientation is characterized by its strong emphasis on the development of students' social interaction skills such as respect, cooperation, and leadership.

Teacher value orientations directly influence teachers' willingness to accept new intervention curricula and/or teaching methods. When teachers' value orientations are inconsistent with the values in the curriculum, they are unable to convey to students a clear message consistent with the curriculum goals (Ennis \& Chen, 1995). Consequently, students have difficulty achieving learning goals and values of the curriculum (Ennis \& Chen, 1995; Ennis \& Zhu, 1991). The inconsistency between teachers' value orientations and the value orientation of an intervention curriculum may impact the success of an intervention that is targeting physical activity motivation and behavior change. Thus, it appears clear that teachers' value orientations are an important variable to examine in curriculum intervention research in order to accurately assess the impact of the curriculum on children's physical activity motivation and behavior change.

Research on teacher value orientations indicates that a curriculum emphasizing clearly defined content and demonstrating values will create an environment where expected behavior can be nurtured. In a series of curriculum intervention studies to investigate the extent to which teachers could be trained to successfully teach a value-laden Sport for Peace curriculum to impact adolescents' in-class physical activity behavior, Ennis (1999a; 1999b; Ennis et al., 1999) found that most disengaged students, many of whom were girls, became willing to change their behavior after their teachers aligned their value orientations with that emphasized in the intervention curriculum.

Situational Interest as a Built-In Motivator in the Curriculum. The physical education curriculum that students interact with on a daily basis is an environmental factor that has powerful influence on student motivation (Newmann, Marks, \& Gamoran, 1996). The curriculum, therefore, can be viewed as what students get energized for, as well as what influences students' internal energizing process. Content that stimulates interest, curiosity, and self-fulfillment serves as an excellent motivator (Burke, 1995). Situational interest, the appealing effect of characteristics in physical activities often referred to by students as "fun," is a naturally built-in motivator in physical education. Studying this variable as an integral part of the model (Figure 1) will help understand how the curriculum can play a role as a situational motivation source to increase students' in-class physical activity and help students internalize and transform situational motivation into self-initiated motivation.

Based on the personal-situational interest conceptualization, Chen and his colleagues investigated the construct of situational interest and its function in physical education (Chen, Darst, \& Pangrazi, 1999, 2001). In these studies, the researchers used multiple samples, video-taped physical activities as perceptual stimuli, and actual participation in physical activities as experiential stimuli to examine adolescents' responses to situational interest in terms of their motivation. It has been found that 
adolescents are likely to be motivated by physical activities with relatively complex movements and skills and that cognitive challenge in physical activities (demanding exploration and high attention) leads to high ratings of situational interest (Chen \& Darst, 2001). Adolescents in these studies did not consider physical activities of a repetitive nature such as jogging, running, and walking as situationally interesting, although these activities have high health-enhancing values. It was also found (Chen et al., 1999, 2001) that high novelty, high attention demand, intensive exploration opportunity, instant enjoyment, and moderate physical challenge are key situational elements for a physical activity to be situationally motivating. Similar results were reported recently for elementary school students as well (Chen, Ennis, Martin, \& Sun, in press).

In a study to investigate the interactive relationship of personal and situational interest, Shen, Chen, Scrabis, and Tolley (2003) have found that high situational interest could overcome the amotivation effect of low personal interest. In a 4-week long middle school dance unit, situational interest was found equally motivating for male and female adolescents, although the males had a much lower personal interest than the females to begin with. Heart rate and step measures demonstrated that male and female adolescents put forth similarly high effort in high situationally interesting lessons. Similar relationship between motivation effects from situational and personal interest were also observed in another study conducted earlier in elementary and middle school physical education classes (Darst, Chen, van der Mars, \& Cusimano, 2001).

The findings clearly demonstrate that situational interest is an important motivator for adolescent physical activity behavior. Situationally interesting physical activities in the curriculum can increase adolescents' motivation to participate in the activities. A situationally interesting physical education curriculum with cognitively challenging activities can motivate adolescents to be active in lessons. As the conceptual model implies (Figure 1), the role of situational interest in the curriculum should be carefully crafted so that it helps adolescents transfer situationally induced motivation to self-initiated motivation for prolonged physical activity behavior change.

\section{Influence of Community}

Community variables, especially community socioeconomic profiles, appear to have strong influence on the effect of physical education curriculum. Linking students' physical activity motivation issues with community environment will provide an opportunity for researchers to examine causality of low motivation from a broader perspective. For instance, the U.S. Department of Education (1996) has reported (1996) that students' access to school sponsored after-school physical activities is restricted by socioeconomic conditions of the community that the school serves. Nationwide, schools in economically deprived urban areas offer two activities fewer in their after-school programs than did schools in affluent suburban areas. Consequently, while $55 \%$ of suburban students choose to participate in school-sponsored after-school sports programs, less than $40 \%$ of students in urban schools are able to do so. Neighborhood socioeconomic status and safety seem to be two critical community variables that may have strong impact on children and adolescent physical activity motivation and behavior. 
Neighborhood Socioeconomic Status. Available research evidence suggests that changing and maintaining physical activity motivation and behavior depend not only on an innovative curriculum, but also on the immediate community environment, especially community socioeconomic profiles (Giles-Corti \& Donovan, 2002) and resources for physical activity (Estabrooks, Lee, \& Gyurcsik, 2003). For example, Estabrooks et al. (2003) reported that significantly fewer physical activity resources are available in neighborhoods of low socioeconomic status, which severely limits access to physical activity in these neighborhoods. These findings are significant in that the connection between physical activity and community is established not only on the physical dimensions of the community (e.g., whether there are sidewalks and playgrounds), but, more importantly, on the socioeconomic profile of the community as a whole (e.g., whether residents can afford equipment or whether it is safe for children to play in the neighborhood).

Students from socioeconomically disadvantaged communties are likely to disengage from the content in physical education (Chen, 1999; Ennis, 1995, 1996). They either show explicitly their disinterest in the content or engage in disruptive activities, investing their motivation in wrong directions (Anderman \& Maehr, 1994). Although fearing failure could demotivate some adolescents, learned helplessness developed chronologically from a disadvantaged home environment certainly contributes to the demonstrated low motivation in some cases (Martinek \& Griffith, 1994). McQuillan (1998) speculates that constantly attributing failure to lack of competence in home and community life forms a negative psychological context for those students to devalue motivated learning behavior. Reflecting on the impact of social change on physical education, the teacher in Chen's case study (1999) affirmatively attributed her students' unmotivated behavior in physical education to reduced after-school physical activity opportunities due to violence and other social problems associated with socioeconomic disadvantages in the inner-city neighborhood.

Neighborhood Safety. Inconsistent evidence has been reported about the relationship between community safety (e.g., crime rate, traffic hazards) and adolescent physical activity motivation and behavior. A recent study on adolescent girls' physical activity found no association between perceived neighborhood safety and physical activity (Kuo, Mekos, Haythornthwaite, \& Young, 2003). However, the Centers for Disease Control and Prevention (CDC) (1999) reported data from five states that showed a relatively strong relationship between perceived crime rate and physical inactivity among the general population. Consistent data were reported in several other studies (Eyler et al., 1998; Sallis, Johnson, Calfas, Caparose, \& Nichols, 1997). Kohl and Hobbs (1998) reasoned that with rising unsafe feelings, children and adolescents may be less motivated to become physically active in their neighborhoods.

In a recent analysis of nationally represented random data involving 21,260 children enrolled in about 1,000 U. S. public and private kindergarten programs, Chen and Zhu (2005) reported that about $70 \%$ of kindergarten children whose parents considered their neighborhood very safe were interested in physical activities, compared with only $50 \%$ in unsafe neighborhoods. The results from a logistic regression analysis suggest that environmental influences from communities and the physical education curriculum play a significantly more important role than 
children's personal factors such as gender, race, BMI, and motor skill. In the total variance accounted for by these factors, $31 \%$ and $32 \%$ were accounted for by the community and curriculum factors, respectively.

\section{Rationale for Adopting the Model in Research}

In most research, personal, curriculum, and community variables were studied in isolation from each other. Historically, physical activity behavior intervention for children and adolescents has targeted personal or community correlates assumed to be effective in bringing about the desired behavior (Sallis et al. 2000). The theoretical significance of the model lies in connecting adolescents' physical activity behavior to their developmentally unique motivation patterns and focusing on the roles of personal, curricular, and community variables in situational-to-self-initiated motivation transition. The literature has shown that the personal, curriculum, and community variables play different roles to either facilitate or hinder the process of internalizing situational motivation into self-initiated motivation.

The personal, curriculum, and community variables function in a nested, associated structure. In this nested structure, the relationship among the variables is dynamically interactive. In other words, changes in one may escalate or constrain effects of others. Very rarely have the effects of this dynamic, structural relationship been investigated. Examining interactive effects of the variables on children and adolescents' physical activity motivation and behavior in this nested structure will enhance our understanding of their influence on the mechanisms of children's physical activity motivation and behavior change.

\section{Focus and Strategy for Future Intervention Research}

\section{The Importance of the Curriculum}

In this integrated model (Figure 1) for research on school-centered physical activity intervention, the curriculum should be the focus of research attention. From descriptive research findings, we have learned that personal and community variables are strongly associated with physical activity behavior. Unfortunately, they are far more difficult to manipulate than school curricula. In other words, their value in intervention programs may be reduced. In addition, it is in the school and physical education that children and adolescents begin to learn about physical activities and the benefits in a meaningful way. Without a careful manipulation of physical education curricula in research, it will be difficult to determine the personal and community variables whose effects on behavior change are curriculum-dependent or curriculum-independent. Identifying and examining the "curriculum-dependency" in personal and community variables will help pinpoint the components of the curriculum that are effective for targeted personal or community variables.

Although community and curriculum influences may account for similar amounts of variance ( $31 \%$ and $32 \%$ ) in children's interest in physical activity (Chen \& Zhu, 2005), curriculum-based intervention can be potentially more effective due to practical controllability. Neighborhood safety, for example, has emerged 
as the most important community variable that relates to children and adolescent physical inactivity at home. It is, unfortunately, a variable beyond the control of either parents or community-based advocates, especially in some inner-city, highcrime neighborhoods. In these communities, schools may be the only safe place where adolescents can participate in physical activities, learn health benefits, and develop motivation and passion for lifelong physically active living. Based on the above review of literature and reasoning, we identify four primary goals for future intervention research.

\section{Goals for Future Intervention Research}

Research Goal 1. From the literature, it is clear that physical education interventions have a strong effect on increasing in-class physical activity. But previous interventions have shown little effect on sustaining a physically active lifestyle (Kahn et al., 2002). We have little research evidence in terms of what weakens the long-term effect of interventions. Thus, it is critical in future research to determine personal, school-curriculum, and community variables that directly contribute to adolescent physical activity motivation and behavior change.

Research Goal 2. From previous research findings, we have learned that it takes time and persistence for children and adolescents to change energetic but sometimes goal-less, spontaneous, situation-based motivation to a goal-oriented, self-initiated motivation (Scheider \& Stevenson, 1999). What we do not know clearly so far is how personal, curriculum, and community variables, functioning in a complex and dynamic web of interactions, either help sustain or impede adolescents' motivation and behavior change over time. It will be worthwhile to explore dynamic relationships of personal, curriculum, and community variables with adolescents' physical activity motivation and behavior over time as these variables simultaneously interact with one another.

Research Goal 3. From previous physical education intervention studies, we have learned that reducing management time and increasing students' in-class activity time is an effective intervention approach (McKenzie, 2001). What is not clear is whether different types of curricula (e.g., a multi-activity centered or a conceptbased curriculum) contribute differently to changing adolescents' self-concept and value system for physical activity. Therefore, it is equally important to determine the extent to which different physical education curricula influence long-term physical activity motivation and behavior change with the effects of personal and community influential variables taken into account.

Research Goal 4. It has become clear in research findings that personal, curriculum, and community variables play either a causal or a mediating role in physical activity motivation and behavior change (Sallis et al., 2000). Little is known, however, about whether the roles remain stable or vary dynamically over time, given their nested, presumably dynamic, and interactive inter-relationships. In order to design effective school- and/or community-based intervention programs, it is critical to distinguish causal or mediating roles of personal, curriculum, and community variables so that they can be targeted appropriately consistent with the development stages of adolescents' physical activity motivation and behavior change. 


\section{Possible Research Strategies}

Although researchers may adopt different methods to accomplish the goals, we provide an example below to illustrate a series of possible strategies that could be used. The examination of the proposed model can be accomplished using two sequentially related steps. First, effects of influential variables will be examined in a set of cross-sectional path models (see Figure 2). The results are expected to address Research Goals 1 and 2, where the individual and collective contributions of the variables to physical activity behavior change can be determined at one point of time. Next, a longitudinal modeling approach will be used to determine the extent to which the roles of the variables change over time in influencing physical activity motivation and behavior change when children and adolescents grow (see Figure $3)$. In the following discussion, we attempt to describe analytical strategies with a few technique terms often used in the structural equation modeling procedures for model testing.

\section{Step 1: Establishing Cross-Sectional Models to Identify the Role of the} Variables. The first step is to examine the cross-sectional path model described in Figure 2 to identify curriculum-dependent and curriculum-independent personal and community variables that influence physical activity motivation and behavior change. Physical Activity will be modeled as directly dependent upon a block of three endogenous Self-initiated Motivation variables, which is itself dependent upon a block of three exogenous Community variables, a block of four exogenous Situation Motivation variables and a block of four exogenous control variables (with the three exogenous variable blocks allowed to co-vary).

The model testing is holistic in that the Self-initiated Motivation variables are placed in the role of mediators to the effects of Community and Situational Motivation variables on Physical Activity, with Control variables being accommodated. An alternative to this will also be modeled, where partial mediation is allowed. That is, direct paths from the exogenous variable blocks to Physical Activity will be tested (shown with dashed paths in Figure 2). If a comparative correlational research design is used where more than one curriculum are taught as in an experimental vs. control study, a comparison of variable effects from different curriculum conditions in causal relationships will be possible. Such a design will allow us to determine, with greater effectiveness than in a simple correlational study, curriculum-dependent and curriculum-independent personal and community variables that contribute to children and adolescent physical activity motivation and behavior change. Such a study will allow us to address Research Goal 1.

It is important that each variable's contribution in determining Physical Activity be assessed so that its role in the process of behavior change can be clarified and that its application in the intervention can be timed for greater intervention effectiveness. Such an assessment can be made by comparing causal pathway models with manipulation of the known determinants in an a priori model. For example, while controlling covariance of other variables in the model, we can test a subset of the situational motivation variables for their direct and indirect effects on Physical Activity; similarly, we can specify and test only a subset of the Self-initiated Motivation variables as mediators or as direct determinants of Physical Activity. The manipulation of the variable effects in the modeling process will help find the variables' individual and collective effects on physical activity behavior change 
due to curriculum or non-curriculum factors. The results will help address Research Goal 2, that is to determine dynamic effects of personal, school curriculum, and community variables on physical activity motivation and behaviors as these variables simultaneously interact with each other to function.

Determination of the most relevant variables in each block and their interactive impact with other variables will be useful for the development of a longitudinal model analysis, if a longitudinal design is used to collect data at multiple points in time (e.g., from elementary school to middle school to high school). With longitudinal data, a set of multi-domain latent growth models can be examined for potential effects of the variables on behavior change encompassing the acclimation, competence, and proficiency stages (see Figure 1).

\section{Step 2: Establishing a Longitudinal Model for Behavior Change Over Time.} The second research step is to develop a longitudinal model that can describe the variables' individual and interactive long-term effects (Research Goals 3 and 4). The longitudinal model can help understand the dynamical role changes of the variables over the years when children grow into adolescents, and into adults. To address Research Goal 3, a longitudinal comparative correlational research design must be used to examine the effects from the variables by comparing at least one intervention and one control curriculum for several years. Because it takes a long time for adolescents to develop expected behavior from the acclimation stage to the proficiency stage and adapt their motivation from situation-dependent to selfinitiated, multi-domain latent growth modeling procedures will be the necessary analytical tool to map out the long-term impact of the influential variables (see Jacobs et al., 2002 on children's motivation change in academics and sports). Using a multi-domain latent growth model (Willett \& Sayer, 1996), the most influential variables in the Situational Motivation and Self-initiated Motivation blocks, concurrent changes in these variables as well as in the dependent variable (Physical Activity) will be modeled, by curriculum conditions, for the time period that the data allow.

There are two general steps in the multi-domain latent growth modeling process. First, the viability of latent growth models will be established separately for each of the three influential variable blocks (as described in Figure 2) (see Duncan, Duncan, Strycker, Li, \& Alpert, 1999; Lawrence \& Hancock, 1998). As shown in the top portion of Figure 3, the modeling process will determine the intercept and slope factors for each variable domain separately (path symbols are omitted for graphic clarity). In the second step, a model combining all three influential variable blocks (see the bottom portion of Figure 3) will be assessed, in which initial amount of (i.e., intercept for) Situational Motivation, Community Atmosphere, Self-initiated Motivation, and Physical Activity, and change rates (slope) in each variable domain model described in the top of Figure 3 will be connected, and their associations will be tested for dynamic, collective impact on behavior change. This completely mediated multi-domain latent growth model can provide substantial information about the role change of each influential variable over time.

Based on the completely mediated growth model, partial mediations (see dashed paths in Figure 3) can be determined by allowing direct relations of initial amount and growth rate from Situational Motivation and Community variables to Physical Activity to vary. This modeling process will address Research Goal 4: to 
model and explain physical activity behavior change pathways to distinguish causal or mediating roles of personal, curriculum, and community variables so that they can be targeted appropriately for future intervention.

\section{Conclusion}

A theoretical model for adolescent physical activity behavior change has been discussed in depth at both conceptual and empirical levels. The conceptual model outlines possible personal, curriculum, and community influential variables that may influence adolescents' physical activity behavior change. The empirical models delineate possibilities to gather and analyze both cross-sectional and longitudinal data needed to examine the efficacy of the conceptual model.

Sustaining a physically active life requires adolescents to have self-initiated motivation that is relatively independent from situationally induced motivators. It is necessary for us to reiterate here that the physical education curriculum, as a central focus of intervention, should emphasize helping adolescents internalize situationally induced motivation into self-initiated motivation. The ability to internalize situational motivation into self-initiated motivation is a key step to sustaining physical activity behavior.

Situational motivators have been central to motivation strategies incorporated in many physical activity intervention programs, such as offering fun activities, or encouraging individuals to partner with friends. But behavior solely based on situational motivation may diminish once the situational motivators are no longer available (e.g., activity partners can no longer exercise together). It is important to understand the role of situational motivation, but it is critical to examine the relationship between situational motivation and self-initiated motivation and the internalization process that helps sustain long-term physical activity behavior. We believe that research studies guided by the proposed conceptual and empirical models will provide useful data for us to better understand the internalization process.

The decline of physical activity is a public issue in our multi-leveled social structure. Using a holistic approach to the research on adolescent physical activity behavior can yield findings meaningful to future interventions at personal, school, and community levels. Methodologically, we believe that the conceptual model can be empirically tested holistically for its effectiveness in explaining the mechanisms of physical activity behavior change in adolescents. The proposed empirical models and the strategy to examine them are logically inter-related. Both crosssectional and longitudinal influence of the targeted variables can be examined to test the tenability of the model. We believe that carefully designed studies on the model will better enable us to understand these targeted influential variables and to design effective intervention programs to motivate adolescents to develop and sustain physically active behavior for life.

\section{References}

Alexander, P.A. (2006). Psychology in learning and teaching. Columbus, OH: PrenticeHall. 
Alexander, P.A., Jetton, T.L., \& Kulikowich, J.M. (1995). Interrelationship of knowledge, interest, and recall: Assessing a model of domain learning. Journal of Educational Psychology, 87, 559-575.

Anderman, E.M., \& Maehr, M.L. (1994). Motivation and schooling in the middle grades. Review of Educational Research, 64, 287-309.

Bandura, A. (1997). The anatomy of stages of change. American Journal of Health Promotion, 12, 8-10.

Baranowski, T., Lin, L.S., Wetter, D.W., Resnicow, K., \& Hearn, M.D. (1997). Theory as mediating variables: Why aren't community interventions working as desired? Annals of Epidemiology, 7, S89-S95.

Beyer, L.E., \& Apple, M.W. (1998). The curriculum (2nd ed.). Albany, NY: SUNY Press.

Burke, D.J. (1995). Connecting content and motivation: Education's missing link. Peabody Journal of Education, 70, 66-81.

Caspersen, C.J., Pereira, M.A., \& Curran, K.M. (2000). Changes in physical activity patterns in the United States, by sex and cross-sectional age. Medicine and Science in Sport and Exercise, 32, 1601-1609.

Centers for Disease Control and Prevention (1999, February). Neighborhood safety and the prevalence of physical inactivity - selected states, 1996. Morbidity and Mortality Weekly Report, 48, 143-146.

Chambliss, H.O. (2004). Behavioral approaches to obesity treatment. Quest, 56, 142-149.

Chen, A. (1999). The impact of social change on inner-city high school physical education: An analysis of a teacher's experiential account. Journal of Teaching in Physical Education, 18, 312-335.

Chen, A., \& Darst, P.W. (2001). Situational interest in physical education: A function of learning task design. Research Quarterly for Exercise and Sport, 72, 150-164.

Chen, A., \& Zhu, W. (2005). Personal and environmental influences on kindergarten children's interest in physical activity. Journal of Physical Activity and Health, 2, 1-15.

Chen, A., Darst, P.W., \& Pangrazi, R.P. (1999). What constitutes situational interest? Validating a construct in physical education. Measurement in Physical Education and Exercise Science, 3, 157-180.

Chen, A., Darst, P.W., \& Pangrazi, R.P. (2001). An examination of situational interest and its sources in physical education. British Journal of Educational Psychology, 71, 383-400.

Chen, A., Ennis, C.D., Martin, R., \& Sun, H. (in press). Situational interest: A curriculum component enhancing motivation to learn. In F. Columbus (Ed.), Progress in Learning Research. Hauppauge, NY: Nova Science Publishers, Inc.

Clifton, R.T., \& Gill, D.L. (1994). Gender differences in self-confidence on a feminine-typed task. Journal of Sport and Exercise Psychology, 16, 150-162.

Corbin, C.B. (2002). Physical activity for everyone: What every physical educator should know about promoting lifelong physical activity. Journal of Teaching in Physical Education, 21, 128-144.

Csikszentmihalyi, M. (1990). Flow: The psychology of optimal experience. New York: Harper \& Row.

Darst, P.W., Chen, A., van der Mars, H., \& Cusimano, B.E. (2001). Teacher, class size, and situational interest: Student responses to fitness routines. Journal of Sport Pedagogy, 7, 43-66.

Dewey, J. (1913). Interest and effort in education. Boston: Houghton Mifflin.

Duncan, T.E., Duncan, S.C., Strycker, L.A., Li, F., \& Alpert, A. (1999). An introduction to latent variable growth curve modeling: Concepts, issues, and applications. Mahwah, NJ: Lawrence Erlbaum Associates.

Eccles, J.S., \& Wigfield, A. (1995). In the mind of the achiever: The structure of adolescents' academic achievement related-beliefs and self-perceptions. Personality and Social Psychology Bulletin, 21, 215-225. 
Ennis, C.D. (1992). Curriculum theory as practiced: Case studies of operationalized value orientations. Journal of Teaching in Physical Education, 11, 358-375.

Ennis, C.D. (1994). Knowledge and beliefs underlying curricular expertise. Quest, 46, 164-175.

Ennis, C.D. (1995). Teachers' responses to noncompliant students: the realities and consequences of a negotiated curriculum. Teaching and Teacher Education, 11, 445-460.

Ennis, C.D. (1996). When avoiding confrontation leads to avoiding content: Disruptive students' impact on curriculum. Journal of Curriculum and Supervision, 11, 145-162.

Ennis, C.D. (1999a). Communicating the value of active, healthy lifestyles to urban students. Quest, 51, 164-169.

Ennis, C.D. (1999b). Creating a culturally relevant curriculum for adolescent girls. Sport, Education, and Society, 4, 31-49.

Ennis, C.D., \& Chen, A. (1993). Domain specifications and content representativeness of the revised Value Orientation Inventory. Research Quarterly for Exercise and Sport, 63, 436-446.

Ennis, C.D., \& Chen, A. (1995). An examination of differences in value orientations between urban and rural physical educators. Research Quarterly for Exercise and Sport, 66, 41-50.

Ennis, C.D., \& Zhu, W. (1991). Value orientations: A description of teachers' goals for student learning. Research Quarterly for Exercise and Sport, 62, 33-40.

Ennis, C.D., Chen, A., \& Ross, J. (1992). Educational value orientations as a theoretical framework for experienced urban teachers' curricular decision making. Journal of Research and Development in Education, 25, 156-164.

Ennis, C.D., Cothran, D.J., \& Loftus, S.J. (1997). The influence of teachers' educational beliefs on their knowledge organization. Journal of Research and Development in Education, 30, 73-86.

Ennis, C.D., Ross, J., \& Chen, A. (1992). The role of value orientations in curricular decision making: A rationale for teachers' goals and expectations. Research Quarterly for Exercise and Sport, 63, 38-47.

Ennis, C.D., Solmon, M.A., Satina, B., Loftus, S.J., Menschi, J. \& McCauley, M.T. (1999). Creating a sense of family in urban schools using the "Sport for Peace" curriculum. Research Quarterly for Exercise and Sport, 70, 273-285.

Estabrooks, P.A., Lee, R.E., \& Gyurcsik, N.C. (2003). Resources for physical activity participation: Does availability and accessibility differ by neighborhood socioeconomic status? Annals of Behavioral Medicine, 25, 100-104.

Eyler, A.A., Baker, E., Cromer, L., King, A.C., Brownson, R.C., \& Donatelle, R.J. (1998). Physical activity and minority women: A qualitative study. Health Education and Behavior, 25, 640-652.

Giles-Corti, B., \& Donovan, R.J. (2002). Socioeconomic status differences in recreational physical activity levels and real and perceived access to a supportive physical environment. Preventive Medicine, 35, 601-611.

Goodlad, J.I. (1984). A place called school: Prospects for the future. New York: McGrawHill.

Harter, S. (1988). Self Perception Profile for Adolescents. (Available from Susan Harter, Dept of Psychology, University of Denver, 2155 S. Race St., Denver, CO 802080204)

Hidi, S. (1990). Interest and its contribution as a mental resource for learning. Review of Educational Research, 60, 549-571.

Hidi, S., \& Anderson, V. (1992). Situational interest and its impact on reading and expository writing. In K.A. Renninger, S. Hidi, \& A. Krapp (Eds.). The role of interest in learning and development (pp. 215-238). Hillsdale, NJ: Lawrence Erlbaum Associates.

Hidi, S., \& Harackiewicz, J.H. (2000). Motivating the academically unmotivated: A critical issue for the 21st century. Review of Educational Research, 70, 151-179. 
Jacobs, J.E., Lanza, S., Osgood, E.W., Eccles, J.S., \& Wigfield, A. (2002). Changes in children's self-competence and values: Gender and domain differences across grades one through twelve. Child Development, 73, 509-527.

Jewett, A.E., Bain, L.L., \& Ennis, C.D. (1995). The curriculum process in physical education. Dubuque, IA: Wm. C. Brown.

Kahn, E.B., Ramsey, L.T., Brownson, R.C., Heath, G.W., Howze, E.H., Powell, K.E., Stone, E.J., Rajab, M.W., Corso, P., \& the Task Force on Community Preventive Services. (2002). The effectiveness of Interventions to Increase Physical Activity: A systematic review. American Journal of Preventive Medicine, 22 (4S), 73-107.

Kohl III, H.W., \& Hobbs, K.E. (1998). Development of physical activity behaviors among children and adolescents. Pediatrics, 101, 549-554.

Krapp, A., Hidi, S., \& Renninger, K.A. (1992). Interest, learning, and development. In K.A. Renninger, S. Hidi, \& A. Krapp (Eds.). The role of interest in learning and development (pp. 1-26). Hillsdale, NJ: Lawrence Erlbaum Associates.

Kuo J., Mekos, D., Haythornthwaite J., \& Rohm Young, D. (2003). Associations among family and neighborhood environment with physical activity in urban adolescent girls. Medicine and Science in Sports and Exercise, 35 (supplement), S65.

Lawrence, F.R., \& Hancock, G.R. (1998). Assessing change over time using latent growth modeling. Measurement and Evaluation in Counseling and Development, 30, 211224.

Lee, A.M., Fredenburg, K., Belcher, D., \& Cleveland, N. (1999). Gender differences in children's conceptions of competence and motivation in physical education. Sport, Education \& Society, 4, 161-175.

Lumpkin, A., \& Avery, M. (1986). Physical education activity program survey. Journal of Teaching in Physical Education, 5,185-197.

Martinek, T.J., \& Griffith, J.B. (1994). Learned helplessness in physical education: A developmental study of causal attributions and task persistence. Journal of Teaching in Physical Education, 13, 108-122.

McKenzie, T.L. (2001). Promoting physical activity in youth: Focus on middle school environments. Quest, 53, 326-334.

McQuillan, P.J. (1998). Educational opportunity in an urban American high school: A cultural analysis. Albany, NY: SUNY Press.

Mitchell, M. (1993). Situational interest. Journal of Educational Psychology, 85, 424436.

Moritz, S.E., Feltz, D.L., Fahrbach, K.R., \& Mack, D.E. (2000). The relation of self-efficacy measures to sport performance: A meta-analytic review. Research Quarterly for Exercise and Sport, 71, 280-294.

Newmann, F.M., Marks, H.M., \& Gamoran, A. (1996). Authentic pedagogy and student performance. American Journal of Education, 104, 280-312.

Pintrich, P.R., \& Schunk, D.H. (2002). Motivation in education: Theory, research and applications (2nd ed.). Englewood Cliffs, NJ: Prentice-Hall.

Prochaska, J.O., \& DiClemente, C.C. (1983). Stages and processes of self-change of smoking: Toward an integrative model of change. Journal of Consulting and Clinical Psychology, 51, 390-395.

Robinson, T.N. (1999). Reducing children's television viewing to prevent obesity. Journal of the American Medical Association, 282, 1561-1567.

Sallis, J.F., Johnson, M.F., Calfas, K.J., Caparosa, S., \& Nichols, J.F. (1997). Assessing perceived physical environmental variables that may influence physical activity. Research Quarterly for Exercise and Sport, 58, 345-351.

Sallis, J.F., Prochaska, J.J., \& Taylor, W.C. (2000). A review of correlates of physical activity of children and adolescents. Medicine and Science in Sport and Exercise, 32, 963-975. 
Sansone, C., \& Smith, J.L. (2000). Interest and self-regulation: The relation between having to and wanting to. In C. Sansone \& J.M. Harackiewicz (Eds). Intrinsic and extrinsic motivation: The search for optimal motivation and performance (pp.343-374). San Diego: Academic Press.

Schneider, B., \& Stevenson, D. (1999). The ambitious generation-America's teenagers: Motivated but directionless. New Haven: The Yale University Press.

Schiefele, U., Krapp, A., \& Winteler, A. (1992). Interest as a predictor of academic achievement: A meta-analysis of research. In K.A. Renninger, S. Hidi, \& A. Krapp (Eds.). The role of interest in learning and development (pp. 183-212). Hillsdale, NJ: Lawrence Erlbaum Associates.

Shen, B., Chen, A., Scrabis, K.A., \& Tolley, H. (2003). Gender and interest-based motivation in learning dance. Journal of Teaching in Physical Education, 22, 396-409.

Stone, E.J., McKenzie, T.L., Welk, G.J., \& Booth, M.L. (1998). Effects of physical activity interventions in youth: Review and synthesis. American Journal of Preventive Medicine, 15, 298-315.

U. S. Dept of Education (1996). National Education Longitudinal Study: 1988-1994. Washington: National Center for Education Statistics, Office of Educational Research and Improvement.

Voorhees, C.C., Clifton, K., Whitt, K., \& Young, D.R. (2004, January). Influence of travel patterns and community environment on daily walking in urban high school girls. Robert Wood Johnson Foundation Active Living Research Annual Meeting. Del Mar, CA.

Wigfield, A. (1994). Expectancy-value theory of achievement motivation: A developmental perspective. Educational Psychology Review, 6, 49-78.

Wigfield, A., \& Eccles, J.S. (1992). The development of achievement task values: A theoretical analysis. Developmental Review, 12, 265-310.

Willett, J.B., \& Sayer, A.G. (1996). Cross-domain analyses of change over time: Combining growth modeling and covariance structure analysis. In G.A. Marcoulides \& R.E. Schumacker (Eds.), Advanced structural equation modeling: Issues and Techniques. Mahwah, NJ: Lawrence Erlbaum Associates, Inc. 